\title{
SOME FIXED POINT THEOREMS FOR MULTI-VALUED MAPPINGS ON REFLEXIVE BANACH SPACES
}

\author{
Valeriu Popa
}

\begin{abstract}
Some fixed point theorems for multi- valued mappings satisfying an implicit relation which generalize the main results from [1] are proved.
\end{abstract}

\section{Introduction}

Let $(X, d)$ be a metric space. We denote $C B(X)$ the set of all non-empty bounded closed subsets of $(X, d)$ and by $H$ the Hausdorff-Pomperu metric on $C B(X)$

$$
H(A, B)=\max \left\{\sup _{x \in A} d(x, B), \sup _{x \in B} d(x, A)\right\}
$$

where $A, B \in C B(X)$ and $d(x, A)=\inf \{d(x, y): y \in A\}$.

Let $T:(X, d) \rightarrow(X, d)$ be a multi-valued mapping. Denote $\Phi(T)=$ $\{x \in X ; x \in T x\}$.

The purpose of this paper is to prove some fixed point theorems for multi-valued mappings satisfying an implicit relation which generalize the main results from [1].

\section{Implicit relations}

Let $\overline{\mathscr{F}}_{6}$ be the set of all real continuous functions $F\left(t_{1}, \ldots, t_{6}\right): R_{+}^{6} \rightarrow R$ satisfying the following conditions:

$\overline{F_{1}}: F$ is non-decreasing in variable $t_{1}$ and non-increasing in variables $t_{5}$ and $t_{6}$;

AMS (MOS) Subject Classification 1991. Primary: 54H25. Secondary: 47H10.

Key words and phrases: multi-valued mapping, common fixed point, implicit relation, reflexiv Banach space. 
$\overline{F_{2}}$ : there exists $h \in(0,1)$ such that for every $u \geq 0, v \geq 0$ with $\left(F_{a}\right): F(u, v, v, u, u+v, 0) \leq 0$ or $F_{g}: F(u, v, u, v, 0, u+v) \leq 0$ we have $u \leq h v$

Ex.1[2].

$$
F\left(t_{1}, \ldots, t_{6}\right)=t_{1}-k \max \left\{t_{2}, t_{3}, t_{4}, \frac{1}{2}\left(t_{5}+t_{6}\right)\right\}
$$

where $k \in(0,1)$.

Ex.2[2]. $\quad F\left(t_{1}, \ldots, t_{6}\right)=t_{2}^{2}-c_{1} \max \left\{t_{2}^{2}, t_{3}^{2}, t_{4}^{2}\right\}-c_{2} \max \left\{t_{3} t_{5}, t_{4} t_{6}\right\}-c_{3} t_{5} t_{6}$, where $c_{1}>0 ; c_{2}, c_{3} \geq 0$ and $c_{1}+2 c_{2}<1$.

Ex.3[2].

$$
F\left(t_{1}, \ldots, t_{6}\right)=t_{1}^{2}-t_{1}\left(a t_{2}+b t_{3}+c t_{4}\right)-d t_{5} t_{6}
$$

where $a>0 ; b, c, d \geq 0$ and $a+b+c<1$.

Ex.4:[2].

$$
F\left(t_{1}, \ldots, t_{6}\right)=t_{1}^{3}-a t_{1}^{2} t_{2}-b t_{1} t_{3} t_{4}-c t_{5}^{2} t_{6}-d t_{5} t_{6}^{2}
$$

where $a>0 ; b, c, d \geq 0$ and $a+b<1$.

Ex.5[2].

$$
F\left(t_{1}, \ldots, t_{6}\right)=t_{1}^{2}-a t_{2}^{2}-b \frac{t_{5} t_{6}}{t_{3}^{2}+t_{4}^{2}+1}
$$

where $0<a<1$ and $b \geq 0$.

\section{Main results}

Definition 1. A set valued-mapping $T: X \rightarrow C B(X)$ is said to have property $(B)$ if the contractive condition defined on $T$ enables us to construct a sequence $\left\{x_{n}\right\}$ for which $d\left(x_{n}, T x_{n}\right) \rightarrow 0$ as $n \rightarrow \infty$.

Theorem 1. Let $X$ be a reflexive Banach space and $T$ a multi-valued mapping of $X$ into the family of non-empty weakly compact subsets of $X$ such that

$$
F(H(T x, T y), d(x, y), d(x, T x), d(y, T y), d(x, T y), d(y, T x)) \leq 0
$$

for all $x, y \in X$ and $F \in \overline{\mathcal{F}_{6}}$. Then $T$ has property $(B)$.

Proof. Let $x_{0}$ be an arbitrary but fixed element of $X$. Choose $x_{1} \in T x_{0}$ such that $d\left(x_{0}, x_{1}\right)=d\left(x_{0}, T x_{0}\right)$. This is possible because $T x_{0}$ is a non-empty weakly compact subset of a reflexive Banach space, hence it is proximal [3, pp. 76]. Inductively we choose $x_{n} \in T x_{n-1}$ so that $d\left(x_{n-1}, x_{n}\right)=d\left(x_{n-1}, T x_{n-1}\right)$. Now

$$
\begin{gathered}
F\left(H\left(T x_{n}, T x_{n+1}\right), d\left(x_{n}, x_{n+1}\right), d\left(x_{n}, T x_{n}\right), d\left(x_{n+1},\right.\right. \\
\left.\left.T x_{n+1}\right), d\left(x_{n}, T x_{n+1}\right), d\left(x_{n+1}, T x_{n}\right)\right) \leq 0
\end{gathered}
$$


which implies succesivelly

$$
\begin{gathered}
F\left(d\left(x_{n+1,} T x_{n+1}\right), d\left(x_{n}, x_{n+1}\right), d\left(x_{n}, T x_{n}\right), d\left(x_{n+1}, T x_{n+1}\right)\right. \\
\left.d\left(x_{n}, x_{n+1}\right), d\left(x_{n+1}, T x_{n+1}\right), 0\right) \leq 0 \\
F\left(d\left(x_{n+1}, T x_{n+1}\right), d\left(x_{n}, T x_{n}\right), d\left(x_{n} ; T x_{n}\right), d\left(x_{n}+1, T x_{n}+1\right),\right. \\
\left.d\left(x_{n}, T x_{n}\right)+d\left(x_{n+1}, T x_{n+1}\right), 0\right) \leq 0 .
\end{gathered}
$$

By $\left(F_{a}\right)$ we have $d\left(x_{n+1}, T x_{n+1}\right) \leq h d\left(x_{n}, T x_{n}\right)$ for each $n=0,1,2, \ldots$ From this is obvious that $d\left(x_{n+1}, T x_{n+1}\right) \leq h^{n+1} d\left(x_{0}, T_{0}\right)$ and convergently $d\left(x_{n}, T x_{n}\right) \rightarrow 0$ as $n \rightarrow \infty$.

Corollary 1. [1] Let $X^{D}$ be a reflexive Banach space and $T$ a multivalued mapping of $X$ into the family of non-empty weakly compact subset of $X$ such that

(2) $H(T x, T y) \leq h \max \left\{d(x, y), d(x, T x), d(y, T y), \frac{1}{2}[d(x, T y)+d(y, T x)]\right\}$ for all $x, y \in X$. Then $T$ has property $(B)$.

Proof. It follows from Theorem 1 and Ex. 1 .

Theorem 2. Let $X$ be a reflexive Banach space and let $T$ be a multivalued mapping of $X$ into the family of all non-empty weakly compact subests of $X$ which satisfies (1). Then $T$ has a fixed point in $X$.

Proof. By Theorem 1 there exists a sequence $\left\{x_{n}\right\} \in X$ for which $d\left(x_{n+1}, T x_{n+1}\right) \leq h d\left(x_{n}, T x_{n}\right)$ for each $n$. Then by a routine calculation can show that $\left\{x_{n}\right\}$ is a Cauchy sequence in $X$.

Let $\left\{x_{n}\right\}$ converge to $p \in X$. Now, by $(1)$, we have

$$
\begin{gathered}
F\left(H\left(T p, T x_{n-1}\right), d\left(p, x_{n-1}\right), d(p, T p), d\left(x_{n-1}, T x_{n-1}\right), d\left(p, T x_{n-1}\right)\right. \\
F\left(d\left(T p, x_{N}\right), d\left(p, x_{n-1}\right), d(p, T p), d\left(x_{n-1}, x_{n}\right), d\left(p, x_{n}\right)+\right. \\
\left.+d\left(x_{n}, T x_{n-1}\right), d\left(x_{n-1}, T_{p}\right)\right) \leq 0
\end{gathered}
$$

Letting $n \rightarrow \infty$ we obtain by continuity of $F$ that

$$
F(d(p, T p), 0, d(p, T p), 0,0, d(p, T p)) \leq 0
$$

which implies by $\left(F_{b}\right)$ that $d(p, T p)=0$. Since $T p$ is closed this shows that $p \in T p$. 
Corollary 2. [1] Let $X$ be a reflexive Banach space and let $T$ be a multi-valued mapping of $X$ into the family of all non-empty weakly compact subsets of $X$ which satisfies (2) for all $x, y \in X$. Then $T$ has a fixed point in $X$.

Proof. It follows form Theorem 2 and Ex. 1.

Theorem 3. Let $T_{1}, T_{2}:(X, d) \rightarrow C B(X)$ be two multi-valued mappings. If

$$
F\left(H\left(T_{1} x, T_{2} y\right), d(x, y), d\left(x, T_{1} x\right), d\left(y, T_{2} y\right), d\left(x, T_{2} y\right), d\left(y, T_{1} x\right)\right) \leq 0
$$

holds for all $x, y \in X$, where $F \in \overline{\mathcal{F}_{6}}$ and $\Phi\left(x_{1}\right) \neq \emptyset$ or $\Phi\left(T_{2}\right) \neq \emptyset$, then $\Phi\left(T_{1}\right)=\Phi\left(T_{2}\right)$.

Proof. If $u \in \Phi\left(T_{1}\right)$, then by (3) we have

$$
F\left(H\left(T_{1} u, T_{2} u\right), d(u, u), d\left(u, T_{1} u\right), d\left(u, T_{2} u\right), d\left(u, T_{2} u\right), d\left(u, T_{1} u\right)\right) \leq 0 .
$$

By $d\left(u, T_{2} u\right) \leq H\left(T_{1} u, T_{2} u\right)$ and $\overline{\left(F_{1}\right)}$ it follows that

$$
\left.F\left(d\left(u, T_{2} u\right), 0,0, d\left(u, T_{2} u\right), d\left(u, T_{2} u\right), 0\right)\right) \leq 0
$$

which implies by $\left(F_{a}\right)$ that $d\left(u, T_{2}\right)=0$. Since $T_{2} u$ is closed this shows that $u \in T_{2} u$ which implies $\Phi\left(T_{1}\right) \subset \Phi\left(T_{2}\right)$. analogous, $\Phi\left(T_{2}\right) \subset \Phi\left(T_{1}\right)$.

Theorem 4. Let $X$ be a reflexive Banach space and $T_{1}$ and $T_{2}$ be multivalued mappings of $X$ into the family of all non-empty weakly compact subsets of $X$. If inequality (3) holds for all $x, y \in X$, where $F \in \overline{F_{6}}$, then $\left(T_{1}\right)$ and $\left(T_{2}\right)$ have a common fixed point and $\Phi\left(T_{1}\right)=\Phi\left(T_{2}\right)$.

Proof. Let $x_{0}$ be an arbitrary but fixed element of $X$ and chose $x_{1} \in$ $T_{2} x_{0}$ and $x_{2} \in T_{1} x_{1}$ so that $d\left(x_{0}, x_{1}\right)=d\left(x_{0}, T_{2} x_{0}\right)$ and $d\left(x_{1}, x_{2}\right)=d\left(x_{1}, T_{1} x_{1}\right)$. Inductively, for $n \geq 1$ we choose $x_{2 n+1} \in T x_{2 n}$ and $x_{2 n+2} \in T_{1} x_{2 n+1}$ so that $d\left(x_{2 n}, x_{2 n+1}\right)=d\left(x_{2 n}, T_{2} x_{2 n}\right)$ and $d\left(x_{2 n+1}, x_{2 n+2}\right)=d\left(x_{2 n+1}, T_{1} x_{2 n+1}\right)$. The existence of such points is guaranteed by the proximality of sets $T_{1} x$ and $T_{2} x$. Now, by (3) we have

$$
\begin{gathered}
F\left(H\left(T_{1} x_{2 n+1}, T_{2} x_{2 n+2}\right), d\left(x_{2 n+1}, x_{2 n+2}\right), d\left(x_{2 n+1}, T_{1} x_{2 n+1}\right), d\left(x_{2 n+2},\right.\right. \\
\left.\left.T_{2} x_{2 n+2}\right), d\left(x_{2 n+1}, T_{2} x_{2 n+2}\right), d\left(x_{2 n+2}, T_{1} x_{2 n+1}\right)\right) \leq 0
\end{gathered}
$$


Hence we have successively

$$
\begin{gathered}
F\left(d\left(x_{2 n+2}, T_{2} x_{2 n+2}\right), d\left(x_{2 n+1}, x_{2 n+2}\right), d\left(x_{2 n+1}, T_{1} x_{2 n+1}\right),\right. \\
\left.d\left(x_{2 n+2}, T_{2} x_{2 n+2}\right), d\left(x_{2 n+1}, x_{2 n+2}\right)+d\left(x_{2 n+2}, T_{2} x_{2 n+2}\right), 0\right) \leq 0, \\
F\left(d\left(x_{2 n+2}, T_{2} x_{2 n+2}\right), d\left(x_{2 n+1}, x_{2 n+1}\right), d\left(x_{2 n+1}, T_{1} x_{2 n+1}\right),\right. \\
\left.d\left(x_{2 n+2}, T_{2} x_{2 n+2}\right), d\left(x_{2 n+1}, T_{1} x_{2 n+1}\right)+d\left(x-2 n+2, T_{2} x_{2 n+2}\right), 0\right) \leq 0 .
\end{gathered}
$$

which implies by $\left(F_{a}\right)$ that

$$
d\left(x_{2 n+2}, T_{2} x_{2 n+2}\right) \leq h d\left(x_{2 n+1}, T_{1} x_{2 n+1}\right) .
$$

Similarly, by $\left(F_{b}\right)$, we have

$$
d\left(x_{2 n+1}, T_{1} x_{2 n+1}\right) \leq h d\left(x_{2 n}, T_{2} x_{2 n}\right) .
$$

By a routine calculation we have that $\left\{x_{n}\right\}$ is a Cauchy sequence in $X$. Let $\left\{x_{n}\right\}$ converge to $p \in X$. By $(3)$ and $\overline{\left(F_{1}\right)}$ we have successively

$$
\begin{gathered}
F\left(H\left(T_{1} x_{2 n+1}, T_{2} p\right), d\left(x_{2 n+1}, p\right), d\left(x_{2 n+1}, T_{1} x_{2 n+1}\right),\right. \\
\left.d\left(p, T_{2} p\right), d\left(x_{2 n+1}, T_{2} p\right), d\left(p, T_{1} x_{2 n+1}\right)\right) \leq 0 \\
F\left(d\left(x_{2 n+2}, T_{2} p\right), d\left(x_{2 n+1}, p\right), d\left(x_{2 n+1}, x_{2 n+2}\right),\right. \\
\left.d\left(p, T_{2} p\right), d\left(x_{2 n+1}, T_{2} p\right), d\left(p, x_{2 n+2}\right)\right) \leq 0
\end{gathered}
$$

Letting $n \rightarrow \infty$ we obtain by continuity of $(F)$ that

$$
F\left(d\left(p, T_{2} p\right), 0,0, d\left(p, T_{2} p\right), d\left(p, T_{2} p\right), 0\right) \leq 0
$$

which implies by $\left(F_{a}\right)$ that $d\left(p, T_{2} p\right)=0$. Since $T_{2} p$ is closed, $p \in T_{2} p$. Thus $p \in \Phi\left(T_{2}\right)$. By Theorem $3 \Phi\left(T_{1}\right)=\Phi\left(T_{2}\right)$.

Corollary 3. [1] Let $X$ be a reflexive Banach space and $S$ and $T$ be the mappings of $X$ into the family fo all non-empty weakly compact subsets of $X$. If for each $x, y \in X$ there exists $h \in(0,1)$ such that

$$
\begin{aligned}
H(S x, T y) & \leq h \max \{d(x, y), d(x, S x), d(y, T y), \\
& \left.\frac{1}{2}[d(x, T y)+d(y, T x)]\right\}
\end{aligned}
$$

then there exists a common fixed point for $S$ and $T$.

Proof. It follows from Theorem 4 and Ex. 1.

Theorem 5. Let $X$ be a reflexive Banach space and let $\left\{T_{n}\right\}$ be a sequence of multi-valued mappings such that $\left\{T_{n}\right\}$ maps $X$ into the family of all 
non-empty wakly compact subsets of $X$. If for each $x, y \in X$ and far positive integer $i$

$$
\begin{array}{r}
F\left(H\left(T_{i} x, T_{i+1} y\right), d(x, y), d\left(x, T_{i} x\right), d\left(y, T_{i+1} y\right)\right. \\
\left.d\left(x_{3}, T_{i+1} y\right), d\left(y, T_{i} x\right)\right) \leq 0
\end{array}
$$

where $\overline{F \mathcal{F}_{6}}$ then the sequence $\left\{T_{r}\right\}$ have a common fixed point and $\Phi\left(T_{1}\right)=$ $\Phi\left(T_{n}\right)$ for $n=2,3, \ldots$

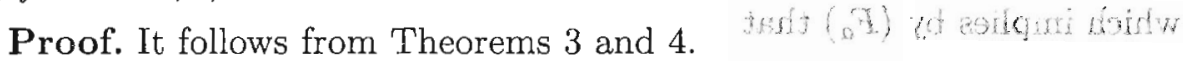

Corollary 4. $[1]$ Let $X$ be a reflexive Banact space and let $\left\{T_{n}\right\}$ be a sequence of multi-valued mappings such that each $\left\{T_{n}\right\}$ maps $X$ into the family of all non-empty weakly compact subsets of $X$. If for each $x, y \in X$ and for positive integers $i$ and $j$

$$
\begin{aligned}
& H\left(T_{j}, T_{j} y\right) \leq h \max \left\{d(x, y), d\left(x_{0} T_{i}\right), d\left(y, T_{j} y\right)\right. \\
& \left(1, \frac{1}{2}\left[d\left(x, T_{j} y\right)+d\left(y, T_{i} x\right)\right]\right\}
\end{aligned}
$$

where $h \in(0,1)$, then there is a cammon fixed point for $T_{n}$

\section{References}

[1] H. Kaneko, A comparasion of contractive condition for multi-valued mappings, Kobe J. Math. 3 (1986), 37-45.

[2] V. Popa, Some fixed point theorems for compatible mappings satisfying an implicit relation, Demonstr. Math. 32 (1999), 157-163.

[3] I. Singer, The Theory of Best Approximation and Functional Analysis, Regional aud Confékences Séries in applüed Math. 13, STAM, 1974: 5.500 Bacau ROMANIA

E-mail: vpopa@ub.ro

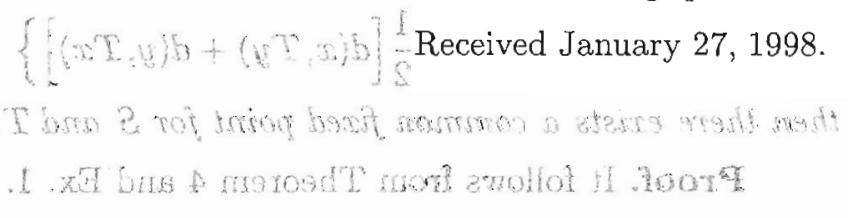

